\title{
O Uso do Texto Literário em sala de aula através da contação de histórias: trabalhando “O Pequeno Príncipe”
}

\author{
Juan Barreto de Brito Silval
}

Resumo: Este manuscrito tem por objetivo utilizar o clássico infanto-juvenil $O$ pequeno príncipe, do autor francês Antoine de Saint-Exupéry, para demonstrar como a ancestral arte da contação de histórias pode ser uma importante ferramenta pedagógica, pois apresenta a literatura de uma maneira lúdica e mais atraente para um público que sabe ler, mas não tem o hábito da leitura. Apoiando-se em estudos desenvolvidos por pesquisadores da área da educação, o texto detalha a metodologia sugerida para se trabalhar uma obra na íntegra, explorando e discutindo seus variados contextos e sua simbologia.

Palavras Chaves: Contação de histórias. Literatura. Aprendizagem. O pequeno príncipe.

\section{The Use of Literary Text in a classroom through storytelling: working "The Little Prince"}

\begin{abstract}
This manuscript aims to use the children's classic The Little Prince, by the French author Antoine de Saint-Exupéry, to demonstrate how the ancient art of storytelling can be an important educational tool because it presentsthe literature in a way playful and more appealing to an audience that knows how to read but do not have the habit of reading. Leaning on studies conducted by researchers from the field of education, the text details the methodology suggested to work a piece in its entirety, exploring and discussing their different contexts and their symbology.
\end{abstract}

Key words: Storytelling. Literature. Learning. The little Prince.

\section{Introdução}

Pesquisas quantitativas apontam que nos últimos vinte anos o Brasil vem diminuindo de forma expressiva seu índice de analfabetismo. Porém, estudos qualitativos recentes nos mostram que uma significativa parcela de jovens (embora alfabetizados) julga a leitura como sendo uma atividade desagradável, e só o fazem quando são obrigados a tal. O objetivo principal desse trabalho é apresentar uma proposta pedagógica alternativa, capaz de intermediar a literatura em sala de aula utilizando uma abordagem que desperte maior interesse dos educandos.

\footnotetext{
${ }^{1}$ Graduado em Letras pela Universidade Federal da Paraíba - UFPB. E-mail: juanbarreto86@ rocketmail.com.
} 


\section{Introdução}

Enxergamos na ancestral técnica narrativa dos contadores de histórias potencial didático capaz de promover o contato do não-leitor com o fascinante mundo das letras. Essa aproximação nem sempre acontece de maneira expontânea, por vezes se faz necessário que alguém (normalmente um educador) intermedie. A dinâmica, a retórica e o lirísmo próprios dessa arte, aliados à experiência empírica e acadêmica do docente podem representar um caminho a ser observado com atenção pelo meio escolar.

$\mathrm{O}$ artigo está dividido em duas partes; a primeira, consiste em enfatizar o fato de que desenvolver no aluno o prazer pela leitura é algo tão primordial quanto ensiná-lo a ler, explicitando como o texto literário pode se tornar mais convidativo através da contação de histórias. Num segundo momento, nos apropriamos do livro O pequeno príncipe, escrito pelo francês Antoine de Saint-Exupéry, para exemplificar como deve ser posto em prática a metodologia desse contar: após disponibilizar uma versão sucinta da trama original (adaptada para se encaixar nos cinquenta minutos que uma aula normalmente oferece) é apresentada uma análise sobre a simbologia presente na obra e, pra finalizar esse processo, uma proposta de exercício de produção textual não tradicional (como uma redação, um teste ou uma ficha de leitura). Autores como Machado (2001), Fernandes (2001), Mantovani (2006), Vassalo (2010), Link (2015) entre outros, fornecem a orientação e o embasamento necessários.

\section{Incutindo o prazer pela leitura através da contação de histórias: o leitor indireto}

A perceptível falta de sintonia existente entre a realidade escolar atual e as necessidades formativas educacionais sugere que os estudos literários não recebem a atenção adequada, logo, pouco acrescentam para o amadurecimento do senso crítico dos aprendentes. Em muitas instituições a literatura sequer figura entre a grade fixa de matérias, aparecendo apenas como um sub-assunto dentro do ensino de Português.

\footnotetext{
A literatura ajuda o aluno a compreender a si mesmo, a sua comunidade e o seu mundo. Todavia, na escola, o ensino da literatura continua reduzido, em geral, à contextualização histórica, caracterização da obra de acordo com o período literário e seu respectivo autor. $\mathrm{O}$ aluno não consegue perceber a plurissignificação do texto literário e os possíveis diálogos entre as obras. (DIAS \& MENEZES, 2014, p. 129)
} 
O livro didático adotado tampouco contribui para mudar esse panorama, é frequentemente inadequado e dificilmente traz uma proposta metodológica que estimule o prazer pela leitura. Seu teor não incentiva o educador a abordar uma obra literária como um todo (explorando seus contextos linguísticos, culturais, filosóficos, entre outros), pelo contrário, apresenta excessiva preocupação em fazer com que os alunos analisem tecnicamente trechos descontextualizados. Outro fator identificado como problemático é o despreparo por parte de alguns docentes. Embora o professor muitas vezes seja impelido a seguir o material didático (ou por exigência da escola ou por pressão dos pais, que querem que se justifique sua compra), ele precisa ter autonomia para não se apoiar de forma excessiva nesse material. É imprescindível ser consciente de que tem diante de si um público que precisa (e quer) ser seduzido e que a literatura é uma disciplina sedutora, capaz de conectar-se a todas as outras.

O que tem se tornado cada vez mais perceptível é que o número de pessoas que não sabiam ler (resquícios de um Brasil de duas décadas atrás, que possuia escandalosos índices de analfabetismo) vem sendo substituido de forma sutil e gradativa por pessoas que passaram a saber, mas não acham essa atividade prazerosa. Esse é um quadro igualmente preocupante, pois quando feita sem prazer a leitura não propicia reflexão, algo imprescindível para a execução de ações cotidianas como se colocar no lugar do outro, pensar em soluções criativas para os problemas e debater apresentando argumentos com coesão e coerência. Acrescentamos o seguinte aspecto a essa discussão:

Em termos bem simples, estou convencida de que o que leva uma criança a ler, antes de mais nada, é o exemplo. Da mesma forma que ela aprende a escovar os dentes, comer com garfo e faca, vestir-se, calçar sapatos, e tantas outras atividades cotidianas. Desde pequena vê os adultos fazendo assim então, também quer fazer. Não é natural, é cultural. Entre os povos onde se come com as mãos, não adianta dar garfo e colher aos meninos, se nunca viram ninguém utilizá-los. (MACHADO, 2001, p. 117)

É papel da família colocar a criança desde cedo em contato com narrativas (contos de fadas antes de dormir ou revistas em quadrinhos, por exemplo), não obstante, a escola deve partilhar da responsabilidade de instigar no jovem aprendiz o gosto pela leitura. É preciso reverter o quanto antes essa imagem negativa formulada sobre os estudos literários, antes que se estabeleça e vire algo complexo de recodificar. Se nós, atuantes na área da educação, 
queremos construir um futuro onde o prazer pela leitura seja algo inerente às próximas gerações, precisamos rever seriamente o modo como isso é desenvolvido atualmente nos nossos alunos.

A contação de histórias se mostra como o ponto de intersecção que faltava entre a arte da literatura e a sua aplicação no âmbito pedagógico. Desde tempos antigos (em que os povos não sabiam ler, mas se reuniam em volta da fogueira para contar seus causos e lendas) os contos estão presentes na formação crítica e moral do homem. Ao ouvirmos uma história, rascunhamos imagens mentais dos seus personagens, dos lugares onde vivem, das roupas que vestem, enfim, de tudo o que nos é descrito oralmente, acionando os mesmos mecanismos acionados se estivessemos lendo.

\begin{abstract}
A história, por si só, acalma, aquieta, provoca a atenciosidade, estimula a observação [...] Contando histórias, é possível: estimular o prazer pela leitura; viajar; percorrer tempos diversos; despertar valores e regras da ética da humanidade; apresentar a harmonia inexistente no planeta; desenhar cenários mentalmente; elaborar personagens; vivenciar emoções tais como segurança/medo, amor/ódio, ganho/perda,prazer/dor, certeza/dúvida, alegria/tristeza, calma/ansiedade, felicidade/angústia; ver diferenças de forma natural; visualizar dificuldades; correlacionar as histórias à vida; sensibilizar para com o ritmo e a sonoridade contidos nas frases; enriquecer o vocabulário; desenvolver a criticidade; conhecer autores e textos. (MANTOVANI, 2006, p. 148)
\end{abstract}

Alguns teóricos utilizam o termo "contador urbano" para denominar o professor que se apropria dessa estratégia para "transformar" os leitores em ouvintes (leitores indiretos) e resgatar seu prazer pelas narrativas. Essa nomenclatura é também uma maneira de diferenciálo do contador popular ancestral. No ambiente de sala de aula, o conceito de turma e platéia se alinham: São espectadores de um discurso, reagindo a ele de maneira positiva ou negativa. Nesse cenário, Regatieri (2008) deixa claro alguns pontos: Primeiramente, contar histórias é diferente de ler histórias (e defende a opinião de que o contador urbano deve utilizar linguagem e dinamismo próprios da fala). Outro ponto salientado é a não obrigatoriedade do professor/contador ser (ou se portar como) um ator, embora considere válido que em seu preparo se beneficie de técnicas básicas, como expressividade facial, vocal e até mesmo corporal. O importante é que o aluno se entusiasme com a sensação de ser coautor (já que também contribuiu mentalmente para acrescentar cor e movimento) e repita esse processo, se aproximando dos livros e conhecendo outras histórias. Aind sobre o contador urbano: 
Precisa desencadear sua mobilização levando-o à identificação e à transferência, de modo a permitir a projeção, no mundo criado, de suas próprias experiências de vida. As emoções vividas durante essa experiência singular devem ser tão significativas que, ao final, esse leitor já não seja o mesmo. Como a comunicação artística só se completa satisfatoriamente quando atinge esse nível de mobilização e resposta. (FERNANDES, 2001, p. 169)

Ao se trabalhar uma obra literária em sala, é indispensável a escolha de um texto apropriado ao nível linguístico e formativo da turma. Os alunos não podem se sentir alheios ao que está sendo dito, pois a consequência natural seria a dispersão. Além disso, o docente deve organizar os processos de representação sequenciando os tópicos a serem debatidos e selecionando quais aspectos serão analisados em cada um. É essencial o professor entender que ele próprio não é o centro das atenções (pois esse é o livro), e sim o mediador que articula os acontecimentos. Narrar estórias (re)aparece como alternativa pedagógica, pois pode conseguir diálogo com quem, à princípio, não estava pré-disposto a qualquer tipo de interação.

A relação da escuta da leitura é afetiva. Este sentimento se manifesta pela identificação com a história, com os temas tratados e com os personagens. Esta identificação consiste em afirmar a sua personalidade graças ao livro, formulando parâmetros de julgamentos éticos com relação aos personagens e de experiências e questionamentos pessoais. Sendo assim, a escuta de histórias tem um caráter formador ético. (SOUZA \& BERNARDINO, 2011, p. 240)

\section{Trabalhando a obra "O Pequeno Príncipe"}

Usaremos o clássico do escritor francês Antoine de Saint-Exupéry (1943) para demonstrar como é possível a simbiose entre o ensino da literatura e a contação de histórias. Para que essa experiência seja bem sucedida partiremos do pressuposto de que o professor terá à sua disposição três aulas, ou seja, um terço do total (se levarmos em consideração que um bimestre escolar normalmente é composto por nove aulas por disciplina, mais uma avaliação).

A justificativa pela escolha dessa obra se deve (em partes) por considerar vantajoso o fascínio prévio que ela desperta. Seus desenhos e citações são disserminados em capas de cadernos, canecas, camisetas, chaveiros e todo tipo de produto comercial há tanto tempo, que o pequeno príncipe passou a permear de forma expressiva o inconsciente coletivo. É bastante 
expressivo o número de pessoas que nunca o leu, mas que são capazes de reconhecer a imagem do garotinho loiro com cachecol e vestes espalhafatosas aonde quer que o veja, além de conseguir identificar alguns elementos do seu universo, como a rosa e a raposa. Outra razão que me motivou a optar por trabalhar esse livro foi sua pluralidade de sentidos e as inúmeras intepretações possíveis de se conceber através dele. O pequeno príncipe é uma história que possui um campo vasto para a investigação e oferece muitas possibilidades.

Dividiremos as três aulas em: Contação, análise, e produção textual. O primeiro encontro será inteiramente dedicado a contação da história. No segundo encontro serão explicados os símbolos presentes na obra e seus respectivos contextos, explorando dois segmentos analíticos específicos (entre os tantos possíveis): A perspectiva extraordinária ${ }^{1}$ (que coloca o príncipezinho como protagonista da história) e a perspectiva ordinária ${ }^{2}$ (tendo o aviador como personagem principal). No terceiro encontro os alunos devem se reunir em grupos de cinco integrantes, escolher uma das cinco sugestões de temas que o professor irá disponibilizar e, como atividade, elaborar até o fim do encontro uma fanfic ${ }^{3}$ baseada na obra O pequeno príncipe.

\section{A Contação}

É importante, antes de mais nada, aclimatar os estudantes à sua não habitual condição de leitores indiretos, primeiramente introduzindo-os a uma breve biografia do autor.

Nascido em 1900 em Lyon (França), Antoine de Saint-Exupéry sempre foi um apaixonado por aviões. Tanto que, aos vinte e um anos, abandonou os estudos de belas artes para se incorporar ao regimento de aviação do serviço militar. Após receber treinamento como piloto em Estrasburgo (Alemanha), ficou encarregado de fazer o correio aéreo entre as bases da Europa e da África. Sua tarefa era levar a correspondência entre Toulouse (França), Dacar (Senegal) e Casablanca (Marrocos) e, para isso, precisava sobrevoar constantemente o deserto do Saara, o segundo maior do mundo. Todo o seu legado literário é uma grande

Fora do comum, insólita.

Convencional, mundana.

Abreviação de fan fiction, termo inglês usado para designar uma modalidade literária que surgiu na internet no final dos anos noventa, onde fãs se apropriam de personagens e cenários de livros já existentes para escrever (sem finalidade comercial ou lucrativa) seus próprios roteiros. 
homenagem à aviação, isso é notório desde o título do seu primeiro conto $O$ aviador (1926), publicado na revista Le navire d'argent. Seu primeiro romance, chamado Correio do Sul (1929), faz alusão ao tempo em que trabalhou como aeropostal. Em Voo Noturno (1931) e Terra dos homens (1939) o autor discorre sobre suas experiências em voos pela Patagônia e na cordilheira dos Andes.

Em 1935, aos comandos de uma aeronave experimental à serviço da Air France, despencou quando sobrevoava o Norte de África e, tendo sobrevivido, teve que caminhar pelo deserto durante alguns dias, até ter sido salvo por uma caravana. Dois anos depois, pilotando o mesmo modelo, escapou à morte com ferimentos graves quando o avião caiu sobre a Guatemala. (LIMA \& SILVA, 2010, p. 4)

Esse acidente na Guatemala lhe acarretou na perda de um olho e o inabilitou a pilotar profissionalmente pelo exército francês na Segunda Guerra Mundial. Piloto de guerra (1942) aborda sua fuga para Nova york, deixando para trás uma Paris ocupada por nazistas. Em $O$ pequeno príncipe (1943), Saint-Exupéry decidiu seguir por uma linha mais lírica e poética, abordando de maneira sutil e metafórica questionamentos existencialistas. Os desenhos facilitam ao leitor visualizar a intenção do autor, o traço infantil e aquarelado das ilustrações adiciona leveza e equilibra o tom profundo que povoa o romance. Embora apareça mais discretamente, seu amor pela aviação mais uma vez é elemento inalienável de sua atmosfera literária. O pequeno príncipe não só é presença pétrea há décadas na lista dos livros mais traduzidos do mundo, como tem a reputação de ser "o livro absoluto, porque é o livro daqueles que leram um só livro.” (LINK, 2015, p. 200). Saint-Exupéry faleceu em 1944, pouco mais de um ano após o lançamento de seu maior sucesso literário, ironicamente vítima de um desastre de avião.

A essa altura, o professor pode iniciar a contação da história propriamente dita.

\section{Análise extraordinária: O Pequeno Príncipe como protagonista}

Sentados em um grande círculo, o docente deve iniciar a segunda aula incentivando os alunos a compartilharem suas impressões sobre o último encontro. É o espaço oportuno para 
se ministrar uma ampla troca de conhecimentos entre aqueles que já conheciam $O$ pequeno príncipe (por terem lido o original ou assistido alguma adaptação para cinema, televisão ou teatro) e os que têm unicamente a contação da história feita pelo professor como referência. $\mathrm{O}$ educador deve conduzir a discussão apresentando a primeira linha de análise: a extraordinária (incomum).

Embora seja o aviador quem narre a história, tudo gira em torno do menino que ele encontra no deserto. Arthur Connan Doyle (1887) fez algo semelhante em sua mais célebre criação; quem nos relata as desventuras é o Doutor Watson, mas o personagem principal é indiscutivelmente o Sherlock Holmes. Ao interpretarmos o pequeno príncipe como sendo o personagem protagonista, podemos observar a obra transcorrer como uma fábula, onde os personagens são geralmente animais (ou forças da natureza) que apresentam características humanas, tais como o raciocínio, a fala e os costumes. Estas histórias geralmente terminam com um ensinamento, uma lição de moral.

A motivação (conflito) que fez o principezinho deixar sua vida comum para trás e partir rumo ao desconhecido foi de origem interna. Ele sentiu a necessidade de um afastamento físico e emocional da rosa para conseguir ponderar com clareza sobre os sentimentos que permeavam a relação dos dois. Decidiu excursionar solitariamente por um pequeno cinturão de asteroides localizados em uma região próxima ao seu planeta. Toda essa parte do livro envolvendo a visita do nosso protagonista aos moradores dos asteroides (o rei, o vaidoso, o empresário, o acendedor de lampiões, o geógrafo e o bêbado), para mim, é uma grande alegoria à maneira que a criança enxerga o adulto: alguém que só sabe mandar, que só ouve elogios, que está sempre de mau-humor, que está sempre ocupado, que não tem total certeza do que julga saber e que tem vergonha de seus defeitos, porém não faz nada para consertá-los.

Foi na terra que o pequeno príncipe encontrou (na figura da raposa) a curva dramática que o fez evoluir como personagem. A raposa é o personagem que mais atribui características fabulosas à história, consolando o menino e lhe ensinando alguns valores. Explicou-lhe através de analogias que cativar era o que acontecia quando a gente confiava em alguém o suficiente para perdermos o medo de nos expor, ensinou que a amizade era um sentimento que precisava ser constantemente bem cuidado, resignificou o conceito de "único" que o principezinho tinha, tornando-o menos literal. Foi a raposa quem fez com que ele percebesse 
que, ainda que houvessem tantas rosas (aparentemente) iguais, o zelo e a admiração que ele dedicava a uma em específico a tornava única.

Segundo narrativa do livro, o menino estava triste porque havia visto várias rosas iguais àquela que ele tinha em seu planeta, quando apareceu uma raposa, ele a convidou para brincar, mas ela informou "não posso brincar contigo, não me cativaram ainda", (p. 67). Segundo ela, "cativar" significa “criar laços afetivos". [...] Essa afirmação significa inteiramente a Amizade. Essa que é muito importante para o ser humano. (LIMA \& SILVA, 2010, pp. 9-10)

O encontro com o aviador foi para o menino, a princípio, apenas mais uma interação com alguma criatura exótica. Essa impessoalidade foi rompida no instante em que o principezinho reconheceu o (até então) indecifrável desenho do elefante engolido inteiro por uma jiboia (cativando o aviador), e quando o aviador lhe concedeu o tão cobiçado carneiro (cativando o pequeno príncipe). Segundo a teoria da raposa, um se identificou com o outro e se tornaram amigos. Posteriormente, esse encontro com o aviador se mostrou crucial. Durante suas conversas, protagonista e coadjuvante compartilharam suas experiências pessoais e se auto analisaram. Ao refletirem, amadureceram. A essa altura, o professor deve abrir um parênteses para destacar a analogia ao ângulo de visão da criança em relação à vida, presente nesse trecho do livro: o receio pelos baobás pode querer simbolizar a natural apreensão sentida em relação à novidade que é crescer. No começo é aparentemente inofensivo, mas depois de um tempo pode destruir tudo o que antes era estável e tranquilo (infância).

$\mathrm{O}$ piloto e o pequeno príncipe caminharam a madrugada inteira em silêncio, procurando um poço que o segundo afirmou ter visto. Quando o encontraram, totalmente sedentos, sua felicidade em beber um simples copo de água obrigou o leitor a parar e pensar em dois aspectos: o primeiro, a criança (pela sua ingenuidade inerente) manteve inabalável a esperança sem desanimar, ainda que seu desejo parecesse algo impossível como achar um poço cheio de água no meio do deserto. O outro, o adulto, se desacostumou a valorizar os pequenos prazeres, como beber água ao ter sede ou contemplar a beleza de um amanhecer e de um pôr-do-sol.

Levantei o balde até sua boca. Ele bebeu, de olhos fechados. Era doce como uma festa. Aquela água era muito mais que um alimento. Nascera da caminhada sob as estrelas, do canto da roldana, do esforço do meu braço. Era boa para o coração, como um presente. Quando eu era pequeno, as luzes da árvore de Natal, a música da 33 missa de meia-noite e a doçura dos sorrisos se refletiam nos presentes que ganhava." (Ibid., p. 78) 
Chegamos ao clímax ${ }^{4}$ da obra, o garoto atravessou mais um ritual de separação, o caminho de volta. "A gente corre o risco de chorar um pouco quando se deixou cativar..." (Ibid.,p. 81), foram essas as palavras que ecoaram na mente do aviador após o principezinho se despedir. $\mathrm{O}$ menino caminhou alguns metros e deixou-se picar pela serpente (que garantiu ser o único jeito de se livrar do corpo pesado e conseguir voltar para casa). Repetiu o clássico feito do herói literário que se sacrifica para atingir seu objetivo. A história se encerrou com duas viagens: O pequeno príncipe regressou ao seu planeta e o aviador à sua sociedade.

\section{Análise Ordinária: O Aviador como personagem central}

Analisando essa mesma história sob o ponto de vista ordinário (comum), a obra perde suas características de fábula e torna-se crível. Nessa perspectiva, o personagem principal é o próprio narrador.

Um homem entristecido, melancólico e entediado com a sociedade sofre um acidente no deserto. Em seu delírio de oito dias, antes de "ser encontrado" (cap. XXVII) por seus companheiros, se depara com sua infância, que lhe diz coisas sobre [...] a necessidade de um reencantamento do mundo (processo de domesticação da natureza). É o lado mais frágil da "filosofia existencial" d'O pequeno príncipe. (LINK, 2015, p. 209)

Tomado pelo pânico e exposto ao fortíssimo calor do Saara, o aviador começou a delirar. Estudos da psicologia infantil afirmam ser comum que crianças criem amigos imaginários para conseguirem lidar com uma fase adversa da vida, nesse caso o nosso protagonista (embora adulto) desencadeia a mesma reação. O aviador materializou uma companhia imaginária que lhe ajudou a suportar aquela situação caótica. Inconscientemente entrou em contato com a sua criança interior.

A criança interior motiva o indivíduo a buscar sua expressão pessoal no mundo
coletivo habitado pelos adultos. Nesse mundo, as expressões individuais são
frequentemente oprimidas, o que afasta o sujeito de sua personalidade, de seus
desejos pessoais. Quando isso acontece, a criança interior precisa se manifestar para
impedir que o contato com a essência divina se perca. Assim como qualquer jovem
criatura, tal criança se revela sempre espontânea: Ora alegre e cheia de vida, ora
impaciente e pirracenta. [...] expressa seus desejos mais íntimos refletindo a reação

$4 \quad$ Em uma narrativa, é o ponto alto de tensão do drama. 
do si mesmo às pressões do mundo externo. Por essa razão, é comum que as pessoas, em situações de dificuldades, desespero e grande pressão tenham reações tidas como infantis. Ocorre que é justamente nesses momentos em que se tende ao retorno para si mesmo; é nesses momentos que se dispõe a ouvir a voz da criança que acompanha o ser humano desde seus primeiros minutos de vida e que justamente por conhecê-lo bem, encontra mais facilmente as soluções para o "eu". (VASSALO, 2010, p. 21)

Não à toa, o pequeno príncipe e o aviador eram os únicos que conseguiam reconhecer o desenho do elefante engolido por uma jiboia, quando todos só viam um chapéu. O príncipe, solitário em um planetinha, era a representação da criança que o aviador foi um dia: Refugiada em seu próprio mundo, longe das complicações dos adultos. Complicações essas, que podemos entender como sendo alguns dos defeitos mais nocivos da personalidade humana: a soberba, a vaidade, a cobiça, o vício, a submissão e a ignorância (representados nos caricatos habitantes dos asteroides visitados).

Em seu passeio pelos seis planetoides (e também pela Terra), o pequeno príncipe encontra autômatos funcionais e não outra coisa, e esses autômatos funcionais são o espelho no qual o aviador se reconhece. Em termos diferenciais, é a determinação o que separa o pequeno príncipe daqueles com os quais se encontra (o que separa a infância do mundo adulto), mas é a intensidade o que separa o pequeno príncipe da natureza (o que separa a infância da natureza). Assim, o humanismo desesperançado de Saint-Exupéry (seu "existencialismo") se funda no possível ou impossível: o regresso à infância. (LINK, 2015, pp. 209-210)

A rosa, por sua vez, foi uma figura essencial para o desenrolar dos acontecimentos, pois provocou ida do eu-lírico (pequeno príncipe) e motivou o seu regresso. Na vida real, Exupéry mantinha um relacionamento conturbado com sua esposa. Em 1931 conheceu em Buenos Aires a salvadorenha Consuelo Suncin de Sandoval, sete meses depois estavam casados. Sua vida conjugal era repleta de discussões, turbulentas crises de ciúmes e infidelidades mútuas. Incomodada por se perceber retratada em uma personagem orgulhosa, mimada e fútil como a rosa, Consuelo escreveu um livro chamado Memórias da rosa (lançado postumamente em 2000) como resposta a $O$ pequeno príncipe, descrevendo em seu relato o finado marido como sendo uma pessoa egoísta, volúvel, autodestrutiva e ingrata.

No clássico francês, a função da rosa não é somente apresentar ao personagem-título o amor genuíno advindo da amizade verdadeira, mas também as decepções que acompanham qualquer relacionamento. Sua mensagem, então, corroboraria a ideia de que, ainda que haja amor, as relações não são perfeitas, pois as pessoas não o são (nem qualquer criatura, como demonstra Exupéry). (VASSALO, 2010, p. 30) 
Não podemos aprisionar a rosa à condição exclusiva de par romântico ou de agente de sedução (o paradoxo da beleza que fascina e os espinhos que ferem). Sua feminilidade dá margem para interpretá-la também dentro de uma simbologia maternal, sendo a fuga do B612 (planeta do pequeno príncipe) um rito de amadurecimento: o corte do cordão umbilical. Sair da casa da mãe para desbravar o desconhecido é uma etapa natural que as pessoas cumprem para evoluírem e se transformarem em "gente grande".

A raposa, na cultura ocidental, simboliza a consciência humana, dada a sua astúcia. Nessa linha analítica, foi exatamente esse o papel que ela desempenhou: O da consciência do protagonista. Um lampejo de sanidade em meio ao caos. Foi a raposa quem conseguiu acalmar a angústia que o eu-lírico sentia. Por ser uma criatura vivida (habituada a fugir dos caçadores, se esconder dos cães e matar galinhas para se alimentar), agiu como a voz da experiência, assumindo postura de entidade sábia que aconselha.

A história terminou como começou: Com uma serpente pondo um ponto final na infância. A ilustração de uma enorme cobra devorando um elefante gerou incompreensão por parte dos adultos (sendo confundido com um chapéu) e fez com que o aviador abdicasse da sua infância, ou pelo menos da sua essência (a imaginação), para ser aceito pelos demais. "Então eu não falava nem de jiboias, nem de florestas virgens, nem de estrelas. Colocava-me ao seu nível." (EXUPÉRY, 1943, p. 9). Outro momento de ruptura foi quando a serpente apareceu no final do livro picando o pequeno príncipe no tornozelo. $\mathrm{O}$ aviador (adulto) se viu novamente obrigado a se despedir de mais uma versão pueril de si mesmo, ainda que imaginária. "O sentimento do irremediável me fez gelar de novo.” (Ibid., p. 84).

Segundo essa linha analítica, galgada no real e no ordinário, toda a história de $O$ pequeno príncipe não passou de um transe, uma alucinação psiquica produzida pela mente de um homem perdido no deserto e exposto a um calor fortíssimo. Desesperado, involuntariamente evocou a ajuda de sua criança interior e ela prontamente atendeu ao seu chamado.

Assim, submetendo-se a uma viagem pelo próprio inconsciente, encontrou, finalmente, o amadurecimento necessário para "individuar-se" e autoconhecer-se, ainda que se submetendo aos sofrimentos dessa difícil jornada. [...] O pequeno príncipe trabalha, ao longo da narrativa, justamente para rejuvenescer a consciência do narrador em relação a si mesmo e ao mundo. Seu deslumbramento diante das coisas tidas como banais pelos adultos encantou o narrador de tal maneira que este se viu, ao término da narrativa, contagiado por essa maneira de agir e pensar. Assim, motivado pelo principezinho, o rígido adulto cedeu lugar à criativa criança $[\ldots]$ 
finalmente caminhando em busca de uma expressão pessoal no mundo coletivo. (VASSALO, 2010, pp. 62-63)

Exupéry deixou certa ambiguidade nas duas últimas ilustrações do livro. $\mathrm{Na}$ penúltima, temos o pequeno príncipe inserido em uma paisagem desértica, com dunas ao fundo e céu estrelado, na gravura seguinte temos praticamente a mesma imagem, porém sem o menino. Esses dois desenhos são partes de uma única representação poética, podemos interpretá-los como sendo a visão de um final que exibe o ciclo natural da vida: as pessoas chegam à esse mundo e pouco tempo depois partem. Em um instante estamos e no outro não (metáfora para a morte), enquanto o universo (indiferente) continua existindo normalmente. Também pode referir-se a um questionamento implícito deixado pelo autor: o pequeno príncipe realmente existiu ou foi tudo um delírio do piloto? As ilustrações podem significar um "antes e depois" da vinda do garoto à terra, mas também podem estar retratando como o aviador via a realidade (no primeiro quadro) e como a realidade de fato era (no segundo quadro).

\section{Produção Textual}

$\mathrm{Na}$ terceira aula direcionaremos o foco da aprendizagem para o desenvolvimento de habilidades e competências. De acordo com Garcia (2005), uma competência implica uma mobilização dos conhecimentos e esquemas que se possui para desenvolver respostas criativas e eficazes para problemas novos. Elaborar uma produção textual, para nós, parece ser o meio mais adequado para consolidar o interesse do leitor (direto ou indireto) pela literatura. Nossa proposta de atividade escrita (direcionada a estudantes do Ensino Médio de qualquer faixa etária) sugere algo mais engenhoso do que uma simples redação. O professor deve dividir a turma em grupos de cinco pessoas, disponibilizar alguns temas baseados na obra $O$ pequeno príncipe e, até o fim da aula, uma fanfic precisa ser produzida e entregue por cada equipe. Não há problema se, por acaso, mais de um grupo escolher o mesmo tema.

A primeira sugestão de tema propõe ao grupo imaginar o que aconteceria se ao invés de ter vindo parar no planeta terra, o pequeno príncipe tivesse resolvido visitar mais alguns asteroides localizados próximos ao seu planeta. Que tipos de habitantes insólitos ele 
encontraria? Quais seriam suas características marcantes? Quais impressões o principezinho levaria desses novos encontros? O grupo deve desenvolver uma história que descreva a passagem do garoto por três novos asteroides, transcrevendo os diálogos entre ele e seus respectivos moradores. A segunda opção recomenda que o grupo imagine o que aconteceria ao aviador, caso o pequeno príncipe jamais tivesse aparecido no deserto. Qual teria sido o seu comportamento? Quais teriam sido os seus pensamentos? O grupo deve desenvolver uma história que descreva os oito dias que o aviador passou perdido. Como ele conseguiu escapar e voltar ao convívio em sociedade? A terceira alternativa indica ao grupo imaginar o que aconteceria se o pequeno príncipe tivesse descido em outro lugar da terra, ao invés da África. Que lugar seria esse? Que tipo de pessoas ou animais ele encontraria? Que experiências o garoto teria com esses seres e como ele faria para voltar ao seu planeta de origem? Como quarta proposta o grupo deve produzir uma narrativa descrevendo as transformações físicas e psicológicas sofridas pela rosa durante a ausência do principezinho. Que tipos de reflexões ela fez enquanto ficava sozinha e a que conclusões chegou? A quinta possibilidade de tema propõe ao grupo agir com autonomia e desenvolver um roteiro original, se atendo à única condição de utilizar os personagens pertencentes ao livro $O$ pequeno príncipe interagindo com personagens de outro(s) universo(s) fictício(s), como o literário, o televisivo, o cinematográfico, o musical, entre outros.

Apesar de não estipularmos um número mínimo ou máximo de páginas, recomendamos a todos os grupos que procurem redigir um texto inventivo, dinâmico, sem receio de ousar na composição das ideias nem na transcrição dos detalhes e que ao final assumam a posição de contadores urbanos e contem seus fanfics para a turma. Após cumprir todas as etapas descritas até então (contação, análise e produção textual), consideramos concluído o processo de trabalhar $O$ pequeno príncipe em sala de aula.

\section{Considerações Finais}

Foi verificado que a ausência de estímulo da família e o incentivo insatisfatório por parte da escola são fatores que reforçam no indivíduo o comportamento de não ter o menor interesse pela literatura, inclusive, adotando a opinião de que ler é um exercício enfadonho e 
sem nenhuma utilidade. Pudemos observar que geralmente os primeiros contatos do aprendente com os livros se dão através de materiais didáticos de qualidade questionável, trabalhados em sala de aula por um mediador que não questiona sua relevância e que se apoia excessivamente neles. O desenvolvimento educacional do aluno acaba sendo prejudicado, pois erroneamente não é dada a devida importância à um aspecto crucial para aquisição do hábito da leitura: Sentir genuinamente o prazer em ler. Sobre esse assunto, entendemos como urgente rever a maneira que os estudos literários são introduzidos e administrados na vida dessa nova geração de supostos leitores. Obras literárias são cnsideradas elementos deveras substanciais para o amadurecimento cultural, intelectual e pessoal do ser humano, no entanto o que se pode perceber é que elas raramente são exploradas em sua totalidade na disciplina de literatura.

O objetivo estipulado por esse trabalho era apresentar uma alternativa pedagógica que fosse capaz de despertar real interesse no não-leitor e atrair o seu olhar para a literatura. Utilizando o célebre $O$ pequeno príncipe, do francês Antoine de Saint-Exupéry, demonstramos como é possível trabalhar uma obra literária em sala de aula sob a ótica da contação de histórias. O contar (que é completamente diferente do relatar) tem o caráter lúdico oriundo das artes cênicas, diferencial necessário para cativar um público inédito. Minuciamos todo o processo metodológico: o fundamento (fazer do espectador um leitor indireto, que ao ouvir uma narrativa aciona os mesmos mecanismos imaginativos que acionaria se estivesse lendo um livro), o planejamento (dispôr de três aulas bimestrais para desenvolver o projeto, dividindo-o em contação, análise e produção textual) e a prática (a primeira aula reservada para que o contador urbano encene a história, a segunda destinada a analisar os símbolos contidos na trama e a terceira dedicada a elaboração de uma atividade escrita que exercite as competências e habilidades do aluno).

Com base nos aspectos problemáticos aos quais nos propomos examinar e mediante as respostas obtidas em nossa pesquisa, concluímos que a literatura tem muito mais a contribuir para o círculo educacional do que aquilo que lhe é extraído, mas é preciso ser ajustada na mesma frequência que o educando para que a comunicação possa existir. A contação de histórias pode representar uma porta de entrada para novos horizontes. 


\section{Referências}

DIAS, Janaina; MENEZES, Tadna. Reflexões sobre o ensino da literatura na sala de aula: Possibilidades e entraves. In: Cadernos do CNLF - Estilística e literatura. Rio de Janeiro, vol. 18, n. 6, 2014, p. 115-134.

FERNANDES, Maria Lúcia Oureiro. O texto no livro didático. In: Intinerários - Revista de Literatura, Araraquar: n. 17-18, 2001, p. 165-177

GARCIA, Lenise. Competências e Habilidades: você sabe lidar com isso? Educação e Ciência Online, Brasília: Universidade de Brasília, 2005. Disponível em: http://www.miniweb.com.br/atualidade/entrevistas/Profa Lenise/Habilidades-Competencias1.pdf Acesso em dezembro de 2015.

LIMA, Aline; SILVA, Antônia. O pequeno príncipe: A importância dos símbolos. 2010. 14 p. Universidade de Santo Amaro, São Paulo.

LINK, Daniel. Infância. In: ALEA - Estudos neolatinos. Rio de Janeiro, vol. 17, n. 2 , p. 199-215, jul/dez 2015.

MACHADO, Ana Maria. Entre vacas e gansos - escola, leitura e literatura. In: Texturas (sobre leituras e escritos). Rio de Janeiro: Editora Nova Fronteira, 2001, p. 111-125.

MANTOVANI, Rosalvo Leal. Contar histórias: técnica e performance. In: Anais do IV Congresso de Pesquisa e Pós- Graduação em Artes Cênicas. Rio de Janeiro, 2006.

REGATIERI, Lazara. Didatismo na contação de histórias. Em extenção. Umberlândia, vol. 7, n.2, 2008 , p. $30-40$.

SAINT-EXUPÉRY, Antoine de. O Pequeno Príncipe. 48ª ed. Rio de Janeiro: Editora Agir, 2009.

SOUZA, Linete Oliveira de; BERNARDINO, Andreza. A contação de histórias como estrátégia pedagógica na Educação Infantil e Ensino Fundamental. Educere et educare - Revista de educação. Cascavel, vol. 6, n. 12, p. 235-249, jul/dez 2011.

VASSALO, Fabiana. Arteterapia em "O pequeno príncipe" - O resgate da criança interior na busca da individuação. 2010. 71 p. Dissertação (Pós-graduação "Strictu senso" em Arteterapia, Educação e Saúde) - Universidade Cândido Mendes, Rio de Janeiro.

\section{Como citar este artigo (Formato ABNT):}

SILVA, J.B.B. O uso do texto literário em sala de aula através da contação de histórias: trabalhando "O Pequeno Príncipe", Id on Line Revista Multidisciplinar e de Psicologia, Outubro de 2016, vol.10, n.31, p. 73-88. ISSN 1981-1179.

Recebido: 15/08/2016.

Aceito: 16/08/2016 